\title{
Assessment of knowledge, practice and perception of menstruation among adult women in the reproductive age group, in Mangalore, India
}

\author{
Shashidhar M. Kotian', Vyom K. Chaudhary², Venkata S. Mutya², Anurag S. Sekhon², \\ Sheetal Sriraman ${ }^{2} *$, Prashasti Prasad ${ }^{2}$
}

\begin{abstract}
${ }^{1}$ Department of Community Medicine, Kasturba Medical College, Manipal University, Mangalore, Karnataka, India
${ }^{2}$ Kasturba Medical College, Manipal University, Mangalore, Karnataka, India
\end{abstract}

Received: 07 August 2017

Accepted: 04 September 2017

\section{*Correspondence:}

Dr. Sheetal Sriraman,

E-mail:sheetal238@gmail.com

Copyright: (c) the author(s), publisher and licensee Medip Academy. This is an open-access article distributed under the terms of the Creative Commons Attribution Non-Commercial License, which permits unrestricted non-commercial use, distribution, and reproduction in any medium, provided the original work is properly cited.

\begin{abstract}
Background: Women often lack knowledge regarding reproductive health including menstruation which can be due to socio-cultural barriers in which they grow up. The present study is aimed at assessing the level of knowledge regarding menstruation and hygienic practices and perceptions during menstruation.

Methods: It was a cross sectional study, conducted among 110 adult women to assess their knowledge regarding menstruation, practices followed during menstruation and their perceptionof menstruation. The collected data was analyzed using SPSS version 17. 0. Chi square test was applied. $\mathrm{P}<0.05$ was considered to be significant.

Results: Only $52 \%$ of the study population has satisfactory knowledge regarding menstruation. Women between 15 to 20 years of age and those from the middle and higher socio-economic groups seem to possess maximum knowledge regarding menstruation. Women of the higher socio-economic group practice better sanitary measures during menstruation with $100 \%$ of them using pads, as compared to women of lower socio economic group who showed a trend of using cloth $(87.5 \%)$. Women of the upper socio-economic class $(42.78 \%)$ had better perception towards menstruation $(\mathrm{p}<0.05)$.

Conclusions: It is very important that lower socio-economic group should be educated about the importance of maintaining hygiene during menstruation by proper health education and equip them with skills regarding safe and hygienic practices to prevent the risk for reproductive tract infections.
\end{abstract}

Keywords: Knowledge, Menstrual hygiene, Perception, Reproductive tract infections, Socio-economic class

\section{INTRODUCTION}

Menstruation is the visible manifestation of cyclic physiologic uterine bleeding due to shedding of the endometrium following invisible interplay of hormones mainly through hypothalamo-pituitary-ovarian axis. ${ }^{1}$ Women often lack knowledge regarding reproductive health including menstruation which can be due to sociocultural barriers in which they grow up. These differences create various problems for them. The need of the hour is to have the information, education and an enabling environment to cope with menstrual issues. ${ }^{2}$

In India, women's perceptions of menstruation vary among different cultures and religions. There are many taboos that women have to face during their menses. There is limited knowledge and many misconceptions about menstruation among women in India before and after their menarche. This usually leads to undue fear, anxiety, and unsanitary practices. The knowledge and 
practices related to menstruation are critically dependent on socio-economic conditions. ${ }^{3}$

Adolescent girls constitute a vulnerable group, particularly in India where female children are neglected. Menstruation is still unfortunately thought of as something that is unclean or dirty in some parts of the Indian society. The reaction to menstruation depends upon the general awareness and knowledge about the subject. Increasing the awareness regarding menstruation among adolescent girls will greatly influence their perception regarding the same. There are several misconceptions and practices regarding menstruation practiced in our society today which may sometimes result in adverse health outcomes. Hygiene-related practices of women have a significant impact on their overall health of women; especially with regard to reproductive tract infections (RTI). The strong association between socio-economic status, menstrual hygiene practices and RTI is a clear indicator that educating women on how to maintain adequate sanitation and hygiene is of at most importance. Women having better knowledge regarding menstrual hygiene and safe practices are more likely to practice adequate sanitation during their menstrual cycle and are therefore less vulnerable to RTI and its consequences. Therefore, increased knowledge about menstruation right from adolescence may help in mitigating the suffering of millions of women. ${ }^{4}$

Studies have shown that women, who lack knowledge about menstruation and the need to observe hygienic menstrual practices, are likely to suffer from RTIs such as pelvic inflammatory diseases and even infertility. ${ }^{5-7}$ Special health care needs and requirements of women during monthly cycle of menstruation are collectively given the term "Menstrual hygiene". 8 Therefore this study was planned with the following objectives.

\section{Objectives}

- To assess the knowledge of women in the reproductive age group regarding menstruation.

- To study the practices of women in the reproductive age group towards maintaining menstrual hygiene.

- To determine the perception of women regarding menstruation.

\section{METHODS}

\section{Study design}

The present study was a cross sectional study, conducted among 110 adult women visiting Government Lady Goschen Hospital, Mangalore and KMC Hospital, Attavar, Mangalore, for a period of one month.

\section{Study subjects}

Adult women of reproductive age group residing in rural Mangalore.

\section{Inclusion and exclusion criteria}

Adult women irrespective of their socio-economic status and who gave their consent were included in the study. Adult women who did not give consent or did not want to participate were excluded from the study.

\section{Sample size}

With $95 \%$ confidence level and $80 \%$ power, assuming $50 \%$ knowledge, the sample size comes to be 96 . By keeping $10 \%$ non-response error, the required sample size would be 110 .

Sample size was determined based on the following calculations:

Formula used was,

$\mathrm{N}=\left(\mathrm{Z} \alpha^{2} \mathrm{PQ}\right) / \mathrm{E}^{2}$

$\mathrm{Z} \alpha$ was taken at $95 \%$ confidence level

$\mathrm{E}=20 \%$ relative precision $(80 \%$ Power $)$

\section{Study tool}

A survey with semi-structured and pre-tested questionnaire was conducted to collect the information on educational status, socioeconomic status, knowledge on menstruation, practices for menstrual hygiene and perception of menstruation.

Questionnaire was divided into 3 parts: A, B and C:

\section{A. Knowledge on menstruation}

This section consists of 10 questions, equal weightage given to each question, with only one correct answer. Participants were awarded one mark for each correct answer and zero for each incorrect answer.

- If total score is $>6$, participant had satisfactory knowledge regarding menstruation.

- If total score is 5-6, participant had average knowledge regarding menstruation.

- If total score is $<5$, participant had below average or poor knowledge regarding menstruation.

\section{B. Practice of menstrual hygiene}

The percentage of the study sample that maintains hygienic practices during menstruation was assessed based on the response to each of the 10 queries.

\section{Perception of menstruation}

The various perceptions on menstruation among the study samples were assessed based on the response to each of the 10 queries. The participant was awarded 5 points for 
the most ideal answer and 1 point for the least ideal answer. Hence, the maximum score in this section would come up to be 50 , whereas the minimum would be 10 .

\section{Statistical analysis}

The collected data was analyzed using SPSS version 17. 0 . For qualitative data statistical test Chi-square was used and $\mathrm{p}<0.05$ was taken as statistically significant.

\section{Ethical clearance}

Institutional ethics committee clearance was obtained prior to the commencement of the study. Permission was then obtained from the Medical Superintendent of Govt. Lady Goshen Hospital, and KMC Hospital, Attavar to carry out the study among female patients of reproductive age group.

\section{Data collection methodology}

The questionnaire was given to all those women in the reproductive age group (between menarche and menopause) who were willing to participate. The willing participants were required to fill a participant information sheet and consent form stating their consent to participate in the same. The information provided by all the participants was kept confidential and only used for research purposes.

\section{RESULTS}

Our study was conducted in a study population of 110 women, in Govt. Lady Goschen Hospital and $\mathrm{KMCH}$, Attavar, Mangalore. Out of our total study population of 110 women, it was found that $29.1 \%$ (32 women) belonged to the lower socio-economic group, 62.7\% (69 women) were from the middle socio-economic group, and $8.2 \%$ ( 9 women) from the higher socio-economic group (Table 1). Majority of the women (44.5\%) were between 20 to 25 years of age and only $13.6 \%$ (15) of the women were above 30 years of age (Table 1).

Table 1: Distribution of age and socio-economic status among the study population $(\mathrm{N}=110)$.

\begin{tabular}{|lll|}
\hline Variables & Frequency & $\%$ \\
\hline Age in years & & \\
\hline $15-20$ & 30 & 27.3 \\
\hline $20-25$ & 49 & 44.5 \\
\hline $25-30$ & 16 & 14.6 \\
\hline$>30$ & 15 & 13.6 \\
\hline Socio-economic status & \\
\hline Lower & 32 & 29.1 \\
\hline Middle & 69 & 62.7 \\
\hline Higher & 9 & 8.2 \\
\hline
\end{tabular}

In the present study, it was observed that $52 \%$ (57 women) of the study population possess satisfactory knowledge regarding menstruation (Table 2). Women between 15 to 20 years of age seem to possess maximum knowledge regarding menstruation with a mean score of 7.6 out of 10 . However, women between 25 to 30 years of age seem to possess minimum knowledge regarding menstruation with a mean score of 5.6 out of 10 . As is obvious from Table 2, women from the lower socioeconomic group possess least amount of knowledge regarding menstruation with their mean score being 5.8 out of 10 which is quiet low compared to women from the middle and higher socio-economic groups.

Table 2: Assessment of menstrual knowledge ( $\mathrm{N}=110)$.

\begin{tabular}{|lcc|}
\hline Variables & Frequency & $\%$ \\
\hline Menstrual knowledge & & \\
\hline Satisfactory & 57 & 52 \\
\hline Average & 29 & 26 \\
\hline Poor & 24 & 22 \\
\hline Variable & Mean score (out of 10) \\
\hline Mean knowledge based on age groups \\
\hline 15 to 20 years & 7.6 \\
\hline 20 to 35 years & 7.0 \\
\hline 25 to 30 years & 5.6 \\
\hline >30 years & 7.0 \\
\hline Mean knowledge based on socio economic status \\
\hline Lower & 5.8 \\
\hline Middle & 7.5 \\
\hline Higher & 7.1 \\
\hline
\end{tabular}

Table 3: Assessment of hygienic practices during menstruation among the study population.

\begin{tabular}{|c|c|c|}
\hline Variables & Fre & $\%$ \\
\hline \multicolumn{3}{|c|}{ Type of Absorbent used $(\mathrm{N}=110)$} \\
\hline Sanitary pads & 64 & 58 \\
\hline Cloth & 46 & 42 \\
\hline \multicolumn{3}{|c|}{ Time of disposal of used cloth $(\mathrm{N}=46)$} \\
\hline After 3 months & 27 & 58 \\
\hline After 4 months & 13 & 29 \\
\hline After 1 year & 5 & 11 \\
\hline After 2 years & 1 & 2 \\
\hline \multicolumn{3}{|c|}{ Method of disposal of used pad or cloth $(\mathrm{N}=110)$} \\
\hline Flushing in toilet & 19 & 17 \\
\hline Throw in dustbin & 88 & 80 \\
\hline Bury in landfills & 2 & 2 \\
\hline Throw on Roads & 1 & 1 \\
\hline \multicolumn{3}{|c|}{ Cleaning genitalia $(\mathbf{N}=110)$} \\
\hline Always & 16 & 14 \\
\hline Occasionally & 39 & 36 \\
\hline Not at all & 55 & 50 \\
\hline
\end{tabular}

Table 3 depicting the hygienic practices during menstruation shows that $64(58 \%)$ women used sanitary pads during menstruation while $46(42 \%)$ used cloth. It is seen that $83 \%$ of women between 15 to 20 years of age used pads as absorbents during menstruation whereas 
women above 30 years of age $(80 \%)$ seem to show a trend of using cloth (Table 4) and the association was found to be statistically significant.

While assessing the hygienic practices during menstruation, the economic status of women cannot be ignored, and in the present study, it was observed that women from the upper socio-economic group seem to practice better sanitary measures with $100 \%$ of the women from this group using pads as absorbents during menstruation compared to $87 \%$ of women from lower socio-economic group who mainly use cloth and the association was also significant (Table 4). From the Table
3 , it was noted that a greater percentage of women $(58 \%)$ who use cloth as an absorbent during their menses, dispose of the used cloth after 3 months (Table 3 ). Regarding the method of disposal of the used material, $80 \%$ women properly disposed the cloth or sanitary pads used; they wrap the cloth or sanitary pad in paper or a plastic cover.

This is a good sign, indicating that maximum number of women $(80 \%)$ dispose of their used absorbent in a hygienic and sanitary manner (Table 3). Cleanliness of external genitalia was satisfactory in case of $50 \%$ women. (Table 3).

Table 4: Association of hygienic practices during menstruation and respondent's age and socio-economic status.

\begin{tabular}{|c|c|c|c|}
\hline \multirow{2}{*}{ Variables } & \multicolumn{2}{|l|}{ Hygienic practices } & \multirow{2}{*}{ P value } \\
\hline & Maintained (pads) $\mathrm{N}=64(\%)$ & Not maintained (cloth) $\mathrm{N}=46(\%)$ & \\
\hline \multicolumn{4}{|c|}{ Age in years } \\
\hline $15-20$ & $25(83)$ & $5(17)$ & $<0.001$ \\
\hline $20-25$ & $27(55)$ & $22(45)$ & \\
\hline $25-30$ & $9(56)$ & $7(44)$ & \\
\hline$>30$ & $3(20)$ & $12(80)$ & \\
\hline \multicolumn{4}{|c|}{ Socio-economic status } \\
\hline Lower & $4(13)$ & $28(87)$ & $<0.001$ \\
\hline Middle & $51(74)$ & $18(26)$ & \\
\hline Higher & $9(100)$ & $0(0)$ & \\
\hline
\end{tabular}

* Chi-square

Table 5: Association of perception regarding menstruation and age and socio-economic status of study population $(\mathrm{N}=110)$.

\begin{tabular}{|lllll|}
\hline Variables & N & Mean & S.D & P value \\
\hline Age in years & & & & $<0.001$ \\
\hline $15-20$ & 30 & 40.9 & 5.06 & 5.88 \\
\hline $20-25$ & 49 & 37.47 & 5.65 & \\
\hline $25-30$ & 16 & 34.50 & 7.19 & \\
\hline$>30$ & 15 & 33.93 & & \\
\hline Socio-economic status & & & 5.74 & $\mathbf{0 0 0 1}$ \\
\hline Lower & 32 & 33.34 & 5.60 & \\
\hline Middle & 69 & 38.73 & 5.31 & \\
\hline Higher & 9 & 42.78 & & \\
\hline
\end{tabular}

* ANOVA (Fishers F test)

Restrictions during menstruations are common as seen in Table 6. The most frequent were restrictions in visiting holy places $(28.2 \%)$ and attending social functions (12.7\%). 16 (14.6\%) women faced restrictions in household activities. As is evident from the Table 5, women from the higher socio-economic group possess a better perception towards menstruation, with their mean score being 42.78 out of 50 . In contrast to this, women from the lower socio-economic group seem to have a significantly lower mean score of 33.34 out of 50 (Table $5)$.

Table 6: Perception of menstruation $(\mathrm{N}=110)$. 


\begin{tabular}{|llll|ll|}
\hline Attribute & $\begin{array}{l}\text { Strongly } \\
\text { disagree }(\%)\end{array}$ & $\begin{array}{l}\text { Disagree } \\
(\%)\end{array}$ & $\begin{array}{l}\text { Neutral } \\
(\%)\end{array}$ & $\begin{array}{l}\text { Agree } \\
(\%)\end{array}$ & $\begin{array}{l}\text { Strongly } \\
\text { agree }(\%)\end{array}$ \\
\hline Menstruation is a curse & $57(51.8)$ & $25(22.7)$ & $16(14.5)$ & $4(3.6)$ & $8(7.3)$ \\
\hline Women should be isolated during menstruation & $63(57.3)$ & $32(28.2)$ & $7(6.4)$ & $5(4.5)$ & $4(3.6)$ \\
\hline $\begin{array}{l}\text { It's okay to do household activities during } \\
\text { menstruation }\end{array}$ & $9(8.2)$ & $7(6.4)$ & $17(15.5)$ & $50(45.5)$ & $27(24.5)$ \\
\hline $\begin{array}{l}\text { It’s okay to do visit holy places during } \\
\text { menstruation }\end{array}$ & $21(19.1)$ & $10(9.1)$ & $30(27.3)$ & $29(26.4)$ & $20(18.2)$ \\
\hline $\begin{array}{l}\text { Women should be restricted from attending } \\
\text { social functions during menstruation }\end{array}$ & $52(47.3)$ & $33(30)$ & $11(10)$ & $2(1.8)$ & $12(10.9)$ \\
\hline $\begin{array}{l}\text { More nutritious diet should be consumed } \\
\text { during menstruation }\end{array}$ & $10(9.1)$ & $8(7.3)$ & $20(18.2)$ & $49(44.5)$ & $23(20.9)$ \\
\hline Talking about menstrual health is embarrassing & $35(31.8)$ & $35(31.8)$ & $17(15.5)$ & $12(10.9)$ & $11(10)$ \\
\hline $\begin{array}{l}\text { I feel comfortable to confide to a relative/friend } \\
\text { regarding my menstrual problems }\end{array}$ & $23(20.9)$ & $46(41.8)$ & $12(10.9)$ & $16(14.5)$ & $13(11.8)$ \\
\hline $\begin{array}{l}\text { I hide my menstrual period from male members } \\
\text { of my family }\end{array}$ & $21(19.1)$ & $26(23.6)$ & $33(30)$ & $17(15.5)$ & $13(11.8)$ \\
\hline $\begin{array}{l}\text { Education regarding menstruation is important } \\
\text { for women }\end{array}$ & $5(4)$ & $7(6)$ & $6(5)$ & $26(23)$ & $66(60)$ \\
\hline
\end{tabular}

\section{DISCUSSION}

Menstrual hygiene is crucial in reproductive life of every woman. It is remarkable that poor menstrual hygiene contribute to reproductive and urinary tract infections. Therefore, adolescent girls should have sound knowledge regarding menstrual hygiene and improve their menstrual hygiene practice. Assessing the knowledge and imparting the knowledge on menstrual hygiene to adolescent girls is one of the essential steps to create the awareness among them. It was observed in this study, that only $89 \%$ of women believed menstruation to be physiological process, whereas in a similar study, $88.3 \%$ believed it to be a physiological process. ${ }^{10}$

Assessment of knowledge regarding menstruation disclosed that $52 \%$ women had satisfactory knowledge regarding menstruation while $26 \%$ women had average knowledge. These observations are found to be more favorable as compared to the study conducted by Anusree et al who had reported $46.7 \%$ of adolescent girls with good knowledge. ${ }^{11}$ Analysis of the association between the level of knowledge regarding menstruation among adult women in reproductive age group and their selected demographic variables (age and socio-economic status) reveals that there was significant association between the level of knowledge and age group ( $\mathrm{p}<0.05)$. It was also evident from the study that there was no significant association between the level of knowledge related to menstruation and socio-economic status ( $p>0.05)$.

A study conducted by Anusree et al reported that there was no association between the knowledge level and age and socio-economic status. ${ }^{11}$
Studies which were reported from India and other developing countries have highlighted the common practices which have prevailed among the adolescent females. ${ }^{4,12}$ The type of absorbent material which is used is of primary concern, since reuse of the material could be a cause for infection if it is improperly cleaned and poorly stored. ${ }^{12}$ This study revealed that most of the low income group women (87\%) used old clothes as menstrual pads and they reused the clothes after washing them with soap and water. They discarded the clothes by throwing them with the routine waste after using it for a few months.

Very few women from the lower income group used sanitary pads (12.5\%) which were available in the market; possibly due to their low socioeconomic status, lesser availability of the pads at the rural areas and lack of awareness. Other researchers, in their studies, also reported that more than three fourth of the girls used cotton clothes and reused them after washing them. ${ }^{6,11,13,14}$

A study from India indicated the use of old cloth material as a frequently used absorbent among (82.5\%) rural and (72.2\%) urban girls. In our study, $42 \%$ women used cloth material as menstrual absorbents, through the practice of cleaning or sanitizing. Our findings are in accordance to those of other studies which were reported from India. ${ }^{11,15}$ Based on his study, Narayana et al suggested that urban girls had better awareness about menstrual hygienic practices than their rural counterparts. ${ }^{16}$ While other studies, that is, Prateek et al, Yerpude and Dasgupta and Sarkar reported higher use of sanitary pads., ${ }^{47,18}$

Cleanliness of the external genitalia was satisfactory (the frequency of cleaning the external genitalia was more 
than 2 times per day) in case of $50 \%$ women. A study which was conducted by another author revealed that only $34.33 \%$ of the girls cleaned their genitalia. ${ }^{6,19}$ Soap and water were the commonest materials which were used.

In the present study, the commonly practiced methods of disposal of the used absorbent were, wrapping it in paper and either disposing it in a place which was used for solid waste disposal or burning it. The same findings were reported by other studies. ${ }^{6,11,17,19}$

Different restrictions were practiced by most of the girls in the present study, possibly due to the different rituals in their communities; the same were practiced by their mothers or other elderly female in the family, due to their ignorance and false perceptions about menstruation. These findings were consistent with those of other studies. ${ }^{6,11,15,16}$

\section{CONCLUSION}

Menstrual hygiene is an issue that needs to be addressed at all levels. A variety of factors are known to affect menstrual behaviors, the most influential ones being economic status and residential status (urban and rural). Awareness regarding the need for information on healthy menstrual practices is very important. It is essential to design a mechanism to address unsanitary menstrual practices.

The present study reveals that knowledge and practices about menstrual hygiene were good among women in the reproductive age group. Only a few women especially in the lower socioeconomic group had poor knowledge regarding menstruation and did not practice adequate sanitation. So it is important to educate this age group about the importance of maintaining hygiene during menstruation by proper health education to equip them with skills regarding safe and hygienic practices so as to enable them to lead a healthy reproductive life and prevent the risk for reproductive tract infections.

\section{ACKNOWLEDGMENTS}

We would like to thank all those who helped and guided us in conducting the study. We would also like to thank our study participants who patiently filled out our questionnaire.

Funding: No funding sources Conflict of interest: None declared

Ethical approval: The study was approved by the Institutional ethics committee from the Medical Superintendent of Govt. Lady Goshen Hospital, and KMC Hospital, Attavar

\section{REFERENCES}

1. Thakre BS, Thakre SS, Reddy M, Rathi N, Pathak K, Ughade S. Menstrual Hygiene: DC Dutta's Textbook of Gynaecology. Volume 8. 6th edition. 2013: 82.

2. Knowledge and Practice among Adolescent School Girls of Saoner, Nagpur District. J Clin Diagnos Res. 2014;5(5):1027-33.

3. Thakur H, Aronsson A, Bansode S, Lundborg CS, Dalvie S, Faxelid E. Knowledge, Practices, and Restrictions Related to Menstruation among Young Women from Low Socioeconomic Community in Mumbai, India. Front Public Health. 2014;2:72.

4. Dasgupta A, Sarkar M. Menstrual Hygiene. How Hygienic is the Adolescent Girl? Indian J Community Med. 2008;33(2):77-80.

5. Kumar A, Srivastava K. Cultural and Social Practices Regarding Menstruation among Adolescent Girls, Social Work in Public Health. 2011;26(6):594604.

6. Mudey AB, Keshwani N, Mudey GA, Goyal RC. A cross-sectional study on the awareness regarding safe and hygienic practices amongst school going adolescent girls in the rural areas of Wardha District. Global J Health Sci. 2010;2(2):225-231.

7. Bhatia JC, Cleland J. Self- reported symptoms of gynaecological morbidity and their treatment in south India. Studies Fam Plann. 1995;26(4):491-5

8. Mehara S. Adolescent Girl: An Indian perspective. MAMTA Health Institute for Mother and Child. New Delhi: Saket; 1995: 75-78.

9. Mishra D. Singh HP. Kuppuswamy's socio economic status scale- A revision. Indian J Pediatr. 2003;70(3):273-4.

10. Sreedhar M, Syed A. Practices of Menstrual hygiene among urban adolescent girls of Hyderabad. Indian $\mathbf{J}$ Basic Appl Med Res. 2014;4(1):478-86.

11. Anusree PC, Roy A, Sara AB, Faseela VCM, Babu GP, Tamrakar A. Knowledge Regarding Menstrual Hygiene among Adolescent Girls in selected school, Mangalore with a View to Develop an Information Booklet. IOSR J Nursing Health Sci. 2014;3(1):5560.

12. EL Gilany A, BadwiK, El. Fedawy S. Menstrual hygiene among adolescent school girls in Mansoura, Egypt. Reproductive Health Matters. 2005;13(26):147-52.

13. Khanna A, Goyal RS, Bhawsar R. Menstrual practices and reproductive problems: A study of adolescent girls in Rajasthan. J Health Management. 2005;7(1):91-7.

14. Quazi SZ, Gaidhane A, Singh D. Beliefs and practices regarding menstruation among the adolescent girls of high schools and junior colleges of the rural areas of Thane district. J DMIMSU. 2006;2:71-76.

15. Kansal S, Singh S, Kumar A. Menstrual Hygiene Practices in Context of Schooling: A Community 
Study Among Rural Adolescent Girls in Varanasi. Indian J Community Med. 2016;41(1):39-44.

16. Narayan KA, Shrivastava DK, Pelto PJ, Veerapmmal S. Puberty rituals, reproductive and health of adolescent schools girls of south India. Asia Pacific Population J. 2001;16:225-38.

17. Bobhate PS, Shrivastava SR. A cross sectional study of knowledge and practices about reproductive health among female adolescents in an Urban Slum of Mumbai. J Fam Reprod Health. 2011;5:117-24.

18. Jogdand K, Yerpude P. A community based study on menstrual hygiene among adolescent girls. Indian $\mathrm{J}$ Matern Child Health. 2011;13:1-6.

19. Omidwar S, Begum K. Factors which influence the hygienic practices during menses among girls from south India: A cross sectional study. Int J Collaborative Res Internal Med Public Health. 2010;2:411-23.

Cite this article as: Kotian SM, Chaudhary VK, Mutya VS, Sekhon AS, Sriraman S, Prasad P. Assessment of knowledge, practice and perception of menstruation among adult women in the reproductive age group, in Mangalore, India. Int J Reprod Contracept Obstet Gynecol 2017;6:4595-4601. 